\title{
MOBILE LIDAR SYSTEM FOR ENVIRONMENTAL MONITORING
}

\author{
Guangyu Zhao', Ming Lian', Yiyun Li ${ }^{1}$, Zheng Duan' ${ }^{1}$, Shiming $\mathrm{Zhu}^{1}$, and Sune Svanberg ${ }^{12^{2 *}}$
}

${ }^{1}$ Center for Optical and Electromagnetic Research, South China Normal University, University City Campus, Guangzhou 510006, China

${ }^{2}$ Department of Physics, Lund University, P.O. Box 118, SE 22100 Lund, Sweden

"Email: sune.svanberg@fysik.lth.se

\begin{abstract}
A versatile mobile remote sensing system for multidisciplinary environmental monitoring tasks on the Chinese scene is described. The system includes a $20 \mathrm{~Hz} \mathrm{Nd}$ :YAG laser-pumped dye laser, optical transmitting/receiving systems with a $30 \mathrm{~cm}$ and a $40 \mathrm{~cm}$ Newtonian telescope, and electronics, all integrated in a laboratory, installed on a Jiefang truck. Results from field experiments on atomic mercury DIAL mapping and remote laser-induced fluorescence and break-down spectroscopy are given.
\end{abstract}

\section{INTRODUCTION}

Environmental issues attract an ever increasing interest, and measures to improve the ambient living conditions are widely launched to reduce the impact of environmental pollution, not the least on the Chinese scene, where the situation is severe (see, e.g. [1]). Laser spectroscopy has proven as a powerful methodology for environmental studies, both in the laboratory and in remote-sensing applications. We here present a new and versatile mobile laboratory, which we have constructed at South China Normal University (SCNU) in Guangzhou. While specially adapted for laser radar applications, is also allows a wide range of laboratory studies to conveniently be pursued out in the field.

\section{SYSTEM DESCRIPTION}

The SCNU lidar system is a mobile unit with a large-size laboratory container, $7.5 \mathrm{~m}$ x $2.4 \mathrm{~m} \times 2.4$ $\mathrm{m}$, integrated on a Jiefang truck. A photograph of the system is shown in Fig. 1. Fig. 2a provides a side view, Fig. $2 b$ a top view, while Fig. $2 \mathrm{c}$ shows the system in its docking position at the fixed SCNU laboratory in Guangzhou. While docked its full infra-structure is available for ordinary laser spectroscopy experiments pursued also in the fixed laboratory. The mobile system, in differential absorption lidar (DIAL) configuration [2],

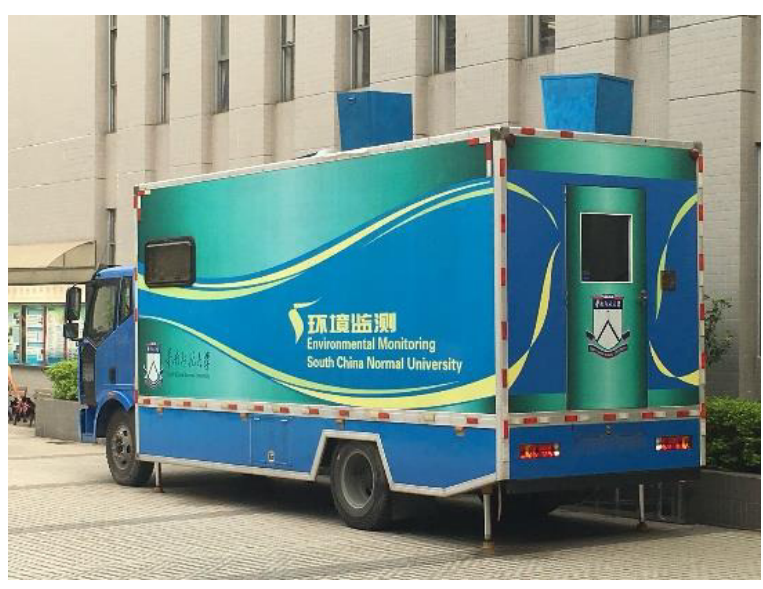

Fig. 1. SCNU mobile remote sensing laboratory.

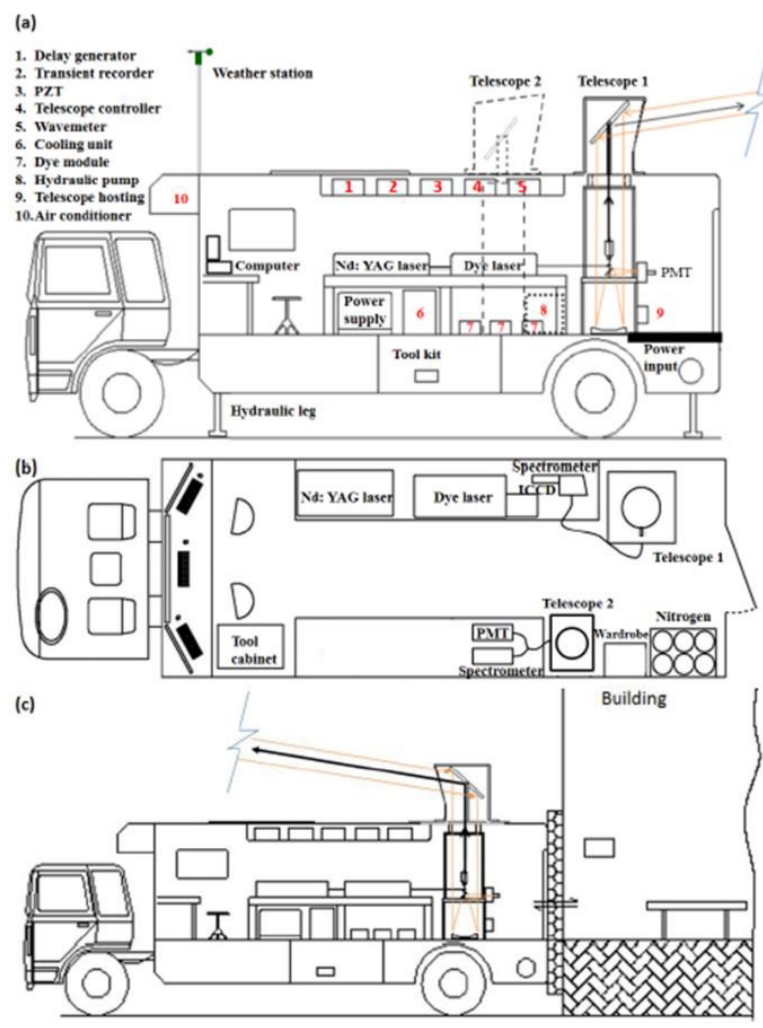

Fig. 2. The SCNU lidar system in side view (a), top view (b) and, docked to the fixed SCNU laboratory in Guangzhou (c). 
operates with a $20 \mathrm{~Hz} \mathrm{Nd:YAG-pumped} \mathrm{dye} \mathrm{laser,}$ which, e.g., for atomic mercury monitoring is operating at $508 \mathrm{~nm}$, frequency doubled to the 254 $\mathrm{nm} \mathrm{Hg}$ absorption line, and providing a mapping range approaching $2 \mathrm{~km}$. The choice of a dye laser, instead of an all-solid-state transmitter, e.g. an optical parametric oscillator (OPO) [3], is motivated by a better adaption to realistic field operating conditions. The system incorporates two vertically looking Newtonian telescopes (diameter 40 , and $30 \mathrm{~cm}$, respectively), both with roof-top folding mirrors. The system is fully controlled by LabVIEW software. A full description of the system and measurement examples are given in [4].

\section{ATMOSPHERIC MONITORING}

Mercury is a particularly severe heavy-metal pollutant [5-8], and is also an interesting geophysical tracer gas $[9,10]$. China uses 500-700 tons of mercury annually and has severe mercury pollution problems in certain areas $[6-8,11]$. We have used the mobile system in measurements of the vertical distribution of atmospheric mercury in the Chinese cities of Guangzhou, Zhengzhou and $\mathrm{Xi}^{\prime}$ an. Concentrations were often found to be around $5 \mathrm{ng} / \mathrm{m}^{3}$. In contrast, very high concentrations were observed in the mercury mining area of Wanshan, Guizhou province. An example of Hg DIAL measurements in this area is shown in Fig. 3, where concentrations in excess of $150 \mathrm{ng} / \mathrm{m}^{3}$ were observed. Our system can readily be used for studying other important atmospheric pollutants, such as $\mathrm{NO}_{2}, \mathrm{SO}_{2}, \mathrm{O}_{3}$, and $\mathrm{NO}$ around 440, 300, 280 and $226 \mathrm{~nm}$, respectively. Examples of recordings relating to $\mathrm{SO}_{2}$ are shown in Fig. 4.

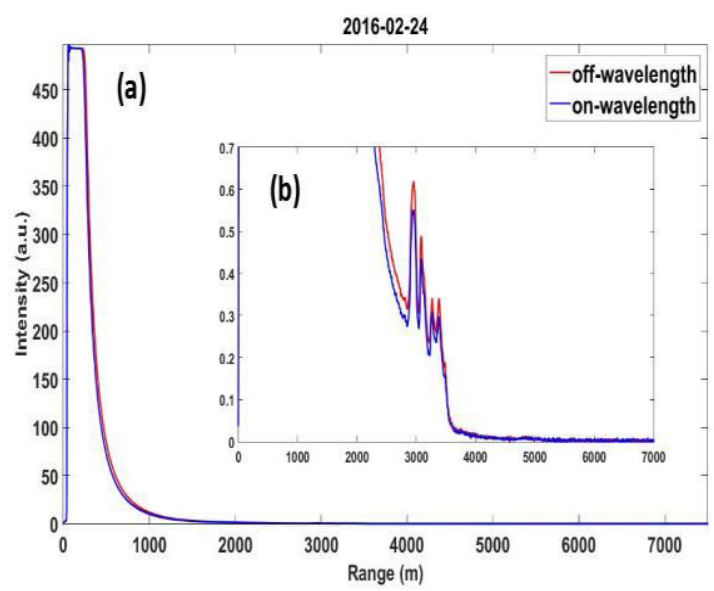

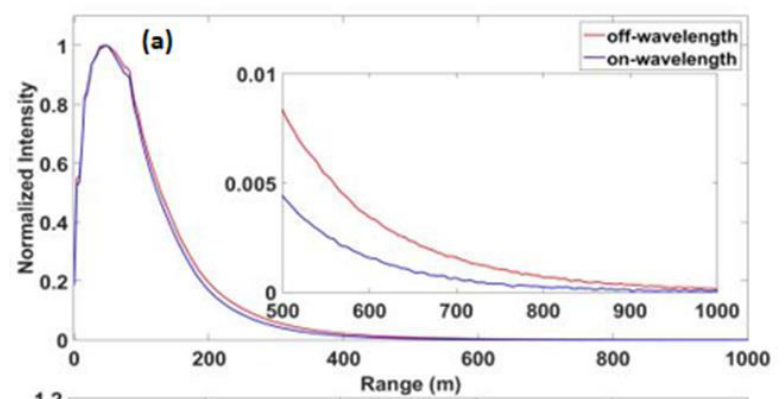
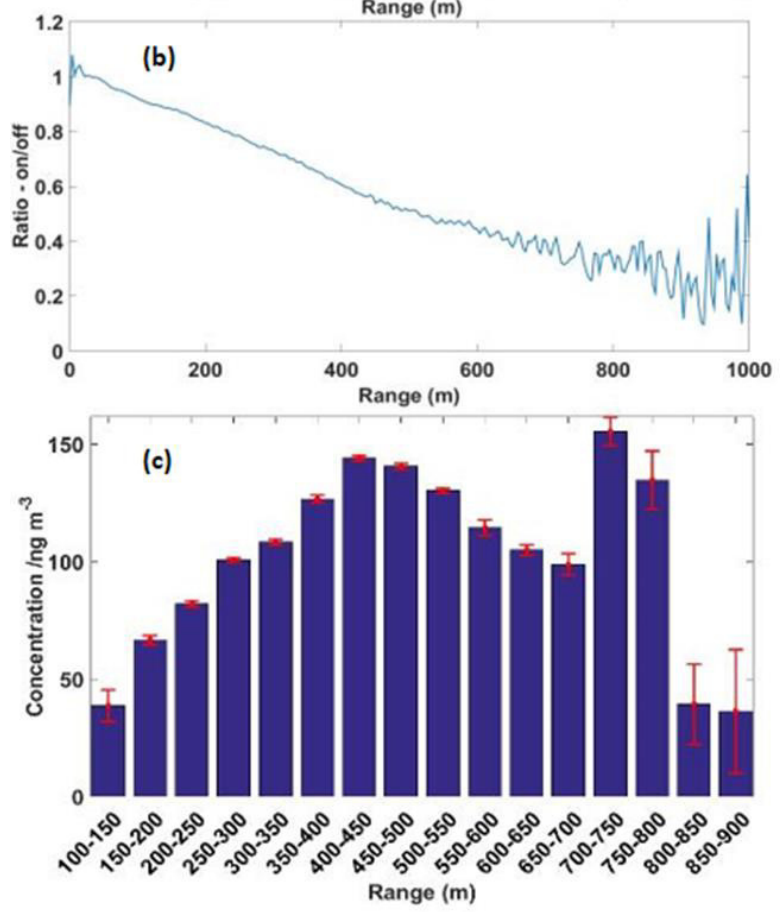

Fig. 3. Differential absorption lidar (DIAL) measurement of atomic mercury in the Wanshan abandoned mercury-mining area in China. a) onand off-resonance lidar returns around $254 \mathrm{~nm} \mathrm{~b}$ ) DIAL curve c) evaluated range-resolved mercury concentrations.

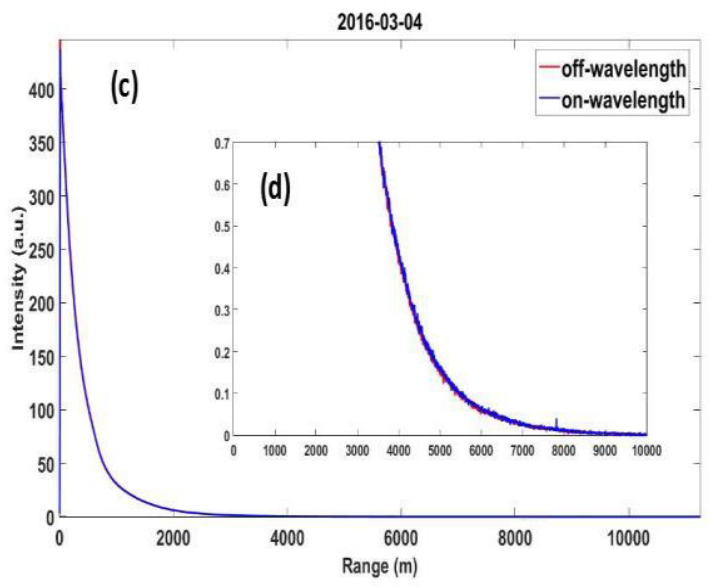

Fig. 4. Lidar curves close to $300 \mathrm{~nm}$ (SO $\mathrm{S}_{2}$ monitoring). a,b) Termination in cloud. c, d) $10 \mathrm{~km}$ return. 

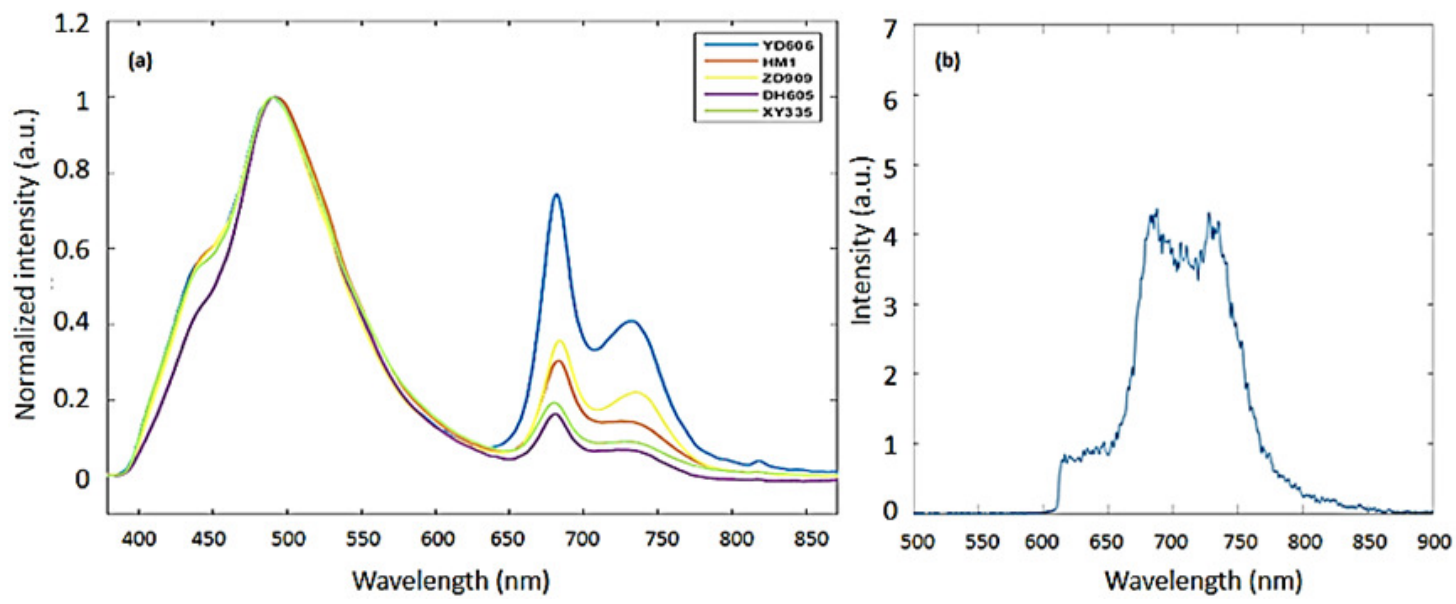

Fig. 5. Laser-induced fluorescence measurements on agricultural crops. a) shows recordings of 5 different types of maize, measured at $30 \mathrm{~m}$ range with $355 \mathrm{~nm}$ excitation. b) shows a recording of rice at $120 \mathrm{~m}$ distance and using $532 \mathrm{~nm}$ excitation.

\section{REMOTE LASER-INDUCED FLUORESCENCE MEASUREMENTS}

Remote laser-induced fluorescence (LIF) measurements enable the monitoring of important properties of solid and liquid targets [12,13]. We have used the new mobile laboratory in field work in Zhengzhou and Xinyang, Henan Province [14]. Examples of recordings of remote vegetation targets (maize and rice) are shown in Fig. 5. Fluorescence properties can yield information on environmental stress and the level of fertilizer available. Likewise, the status of facades of historical buildings can be assessed [15]. A spectrometer is fiber-optically coupled to the output of the lidar receiving telescope in these measurements, where harmonics of the Nd:YAG laser (at 532, 355, or $266 \mathrm{~nm}$ ) can be utilized. For day-light recordings, influence of ambient light is suppressed by using a gated and intensified detector.

\section{REMOTE LASER-INDUCED BREAK- DOWN SPECTROSCOPY MEASUREMENTS}

Laser-induced break-down spectroscopy (LIBS) is a much employed technique for studying the elemental composition of samples, mostly in the laboratory environment [16]. It is also possible to perform LIBS remotely using a lidar system $[17,18]$. We have used our new mobile system for such measurements, and an example is shown in Fig. 6. A soil sample is measured at $15 \mathrm{~m}$ distance, as well as in the laboratory. A spectrometer with a gated and intensified detector was again used, in

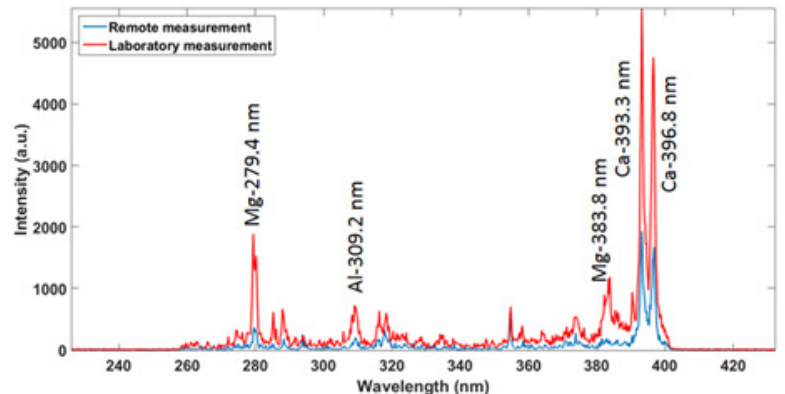

Fig. 6. LIBS recordings for a soil sample located at $15 \mathrm{~m}$ distance from the measurement system, as well as when kept in the laboratory are shown, with sharp spectral lines due to $\mathrm{Mg}, \mathrm{Al}$, and Ca.

order to allow delayed spectral monitoring of the recombining plasma, which then exhibits a multitude of sharp and characteristic elemental spectral lines. The availability of nutrients can be assessed, as well as the presence of, e.g. heavymetal soil pollutants.

Further measurement examples will be discussed.

\section{ACKNOWLEDGEMENTS}

We much value the support by Prof. Sailing He, and Dr. Liang Mei, and the fruitful collaboration with colleagues at the Chinese Academy of Sciences Institute for Geochemistry, Guiyang, at the Henan Agricultural University, Zhengzhou, and the Henan and Guangdong Academies of Agricultural Sciences. This work was supported by the Guangdong Province Innovation Team Research Program (No. 201001D0104799318). 


\section{References}

[1] K. He, H. Huo, and Q. Zhang, Urban air pollution in China: Current status, characteristics, and progress, Annual Review of Energy and the Environment, vol. 27, pp. 397431, 2002.

[2] 2. S. Svanberg, Differential Absorption Lidar (DIAL), in Air Monitoring by Spectroscopic Techniques, M. Sigrist (ed.), Wiley, N.Y. 1994, p. 8

[3] P. Weibring, H. Edner, and S. Svanberg, Versatile mobile lidar system for environmental monitoring, Applied Optics 42, 3583 (2003).

[4] G.Y. Zhao, M. Lian, Y.Y. Li, Z. Duan, S.M. Zhu, L. Mei, and S. Svanberg, Mobile lidar system for environmental monitoring, Appl. Opt., in press (2017)

[5] International Conference on Mercury as a Global Pollutant, with the latest version arranged in 2015 in Korea; http://mercury2015.com

[6] X. Fu, X. Feng, J. Sommar, and S. Wang, A review of studies on atmospheric mercury in China, Science of the Total Environment 421422, 73-81 (2012).

[7] D.G. Streets, J.M. Hao, Y. Wu, J.K. Jiang, M. Chan, H.Z. Tian, and X.B. Feng, Antropogenic mercury emissions in China, Atmos. Env. 39, 7789-7806 (2005).

[8] L. Zhang and M.H. Wong, Environmental mercury contamination in China: Sources and impacts, Environment International 33, 108-121 (2007).

[9] J. H. McCarthy, Jr., W. W. Vaughn, R. E. Learned, and J. L. Meuschke, Mercury in soil gas and air - A potential tool in mineral exploration," Geological Survey Circular 609 (US Geological Survey, Washington 1969).

[10] S. Svanberg, Geophysical gas monitoring using optical techniques: Volcanoes, geothermal fields and mines, Optics and Lasers in Engineering 37, 245 (2002).
[11] Z.H. Dai, X.B. Feng, J. Sommar, P. Li, and X.W. $\mathrm{Fu}$, Spatial distribution of mercury deposition fluxes in Wanshan $\mathrm{Hg}$ mining area, Guizhou province, China, Atmos. Chem. Phys. 12, 6207 (2012).

[12] S. Svanberg, Fluorescence spectroscopy and imaging of lidar targets, Chapter 7 in T. Fujii and T. Fukuchi (Eds) Laser Remote Sensing (CRC Press, Boca Raton 2005) pp 433-467.

[13] H. Amann, Laser spectroscopy for monitoring and research in the ocean, Phys. Scripta T78, 68 (1998).

[14] G.Y. Zhao, Z. Duan, M. Lian, Y.Y. Li, R.P. Chen, J.D. Hu, S. Svanberg, and Y.L. Han, Reflectance and fluorescence characterization of maize species using laboratory measurements and lidar remote sensing, Applied Optics 55, 5273 (2016).

[15] V. Raimondi, G. Cecchi, D. Lognoli, L. Palombi, R. Grönlund, A. Johansson, S. Svanberg, K. Barup, and J. Hällström, The fluorescence LIDAR technique for the remote sensing of photoautotrophic biodeteriogens on outdoor cultural heritage: A decade of in situ experiments, International Biodeterioration \& Biodegradation (2009), doi:10.1016/ j.biod.2009.03.006.

[16] D. A. Cremers, and L. J. Radziemski, Handbook of Laser-Induced Breakdown Spectroscopy (John Wiley \& Sons Ltd., West Sussex, UK, 2006).

[17] S. Palanco, J.M. Baena, and J.J. Laserna, Openpath laser-induced plasma spectrometry for remote analytical measurements on solid surfaces, Spectrochim. Acta B 57, 591 (2002)

[18] R. Grönlund, M. Lundqvist, and S. Svanberg, Remote imaging laser-induced break-down spectroscopy and remote cultural heritage ablative cleaning, Opt. Lett. 30, 2882 (2005). 